\title{
EM BUSCA DE CAMINHOS QUE PROMOVAM A MELHORA DA CONVIVÊNCIA NA ESCOLA: INVESTIGANDO O CLIMA ESCOLAR
}

\author{
Juliana Aparecida Matias Zechi ${ }^{1}$, Monique Luzia de Souza ${ }^{2}$, Ana Elisa Magalhães Tristão Sousa ${ }^{3}$ \\ ${ }^{1}$ Doutora em Educação pela Universidade Estadual Paulista - UNESP, Faculdade de Ciências e Tecnologia - FCT, \\ Presidente Prudente SP. Docente da Universidade Federal de Mato Grosso do Sul - UFMS. Membro do GEPEM \\ UNICAMP/UNESP.E-mail: juzechi@hotmail.com \\ ${ }^{2}$ Mestranda no programa de Pós-graduação em Psicologia Experimental: Análise do Comportamento da Pontifícia \\ Universidade Católica de São Paulo - PUC-SP. \\ ${ }^{3}$ Graduada em psicologia pela Universidade Federal de Mato Grosso do Sul - UFMS.
}

\section{RESUMO}

A presente pesquisa tem como objetivo compreender e avaliar o clima escolar em alunos, docentes e gestores, buscando subsídios que orientem a elaboração de ações para a melhora da convivência escolar. Entende-se por clima escolar o conjunto das percepções dos membros da comunidade educativa em relação à instituição de ensino que envolve fatores relacionados às estruturas pedagógica e administrativa, à organização e as relações sociais que ocorrem neste ambiente. A avaliação do clima escolar se deu por meio de questionários direcionados a alunos, professores e gestores abrangendo oito dimensões que compõem o clima. Foram aplicados 400 questionários em uma instituição da rede pública estadual de ensino fundamental e médio. Os atores escolares, de modo geral, tiveram uma percepção positiva sobre as dimensões do clima escolar. Contudo, a análise dos itens que compõem as dimensões revela pontos negativos e que se contestam entre os participantes. As "situações de intimidação entre os alunos" foram avaliadas positivamente entre os discentes; em contraponto, parte dos professores tiveram uma percepção negativa. Destacaram-se como dimensões avaliadas mais negativamente pelos discentes a "infraestrutura e a rede física da escola" e "família, escola e comunidade"; nestas as respostas dos professores se dividiram, predominantemente, entre neutra e positiva; metade dos gestores avaliaram negativamente a infraestrutura institucional. Também a "gestão e a participação" foram avaliadas negativamente pela metade dos docentes. Por fim, o diagnóstico realizado permite um maior conhecimento sobre o clima escolar contribuindo com a elaboração de propostas de intervenções visando a melhora da qualidade da convivência na escola.

Palavras - chave: Clima Escolar. Convivência. Aluno. Professor. Gestor.

\section{IN SEARCH OF PATHWAYS THAT PROMOTE THE IMPROVEMENT OF COEXISTENCE IN SCHOOL: INVESTIGATING THE SCHOOL CLIMATE}

\begin{abstract}
The present research aims to understand and evaluate the school climate in students, teachers and managers, seeking subsidies that guide the elaboration of actions to improve school coexistence. The school climate is understood as the set of perceptions of the members of the educational community in relation to the educational institution that involves factors related to the pedagogical and administrative structures, the organization and the social relations that occur in this environment. The evaluation of school climate was made through questionnaires addressed to students, teachers and managers covering eight dimensions that compose the climate. A total of 400 questionnaires were administered at a primary and secondary institution from the state public school system. The school actors, in general, had a positive perception about the dimensions of the school climate. However, the analysis of the itens that make up the dimensions reveals negative points which are contested among the participants. The "situations of intimidation among the students" were evaluated positively among the students; in counterpoint, some of the teachers had a negative perception. The "infrastructure and physical network of the school" and "family, school and community" were more negatively evaluated by students; in these the answers of the teachers were divided, predominantly, between neutral and positive; half of the managers negatively
\end{abstract}


evaluated the institutional infrastructure. Also, "management and participation" were negatively evaluated by half of the teachers. Finally, the diagnosis made allows a greater knowledge about the school climate, contributing with the elaboration of proposals of interventions aiming at improving the quality of the coexistence in school.

Keywords: School climate. Coexistence. Student. Teacher. Manager.

\section{INTRODUÇÃO}

Problemas que incidem nas relações interpessoais em meio escolar, como os conflitos entre pares, a indisciplina e a violência, são fruto de constante preocupação entre educadores e apontam para a necessidade de se buscar estratégias que possam melhorar a convivência nas escolas.

Estudos apontam que as relações conflituosas refletem diretamente na qualidade do clima escolar (BLAYA, et. al., 2006; CUNHA, 2014; VINHA; et. al., 2016, MORO, 2018). Em revisão de literatura sobre o tema, Vinha et. al. (2016) afirmam que um clima positivo colabora para o desempenho acadêmico e desenvolvimento saudável dos alunos, também promove a permanência do professor na escola, o que afeta de maneira positiva o processo de ensino-aprendizagem de qualidade. Por outro lado, um clima escolar negativo intensifica os problemas na aprendizagem e nas relações interpessoais estabelecidas no contexto institucional.

Desse modo, pesquisadores e educadores reconhecem a importância de compreender e analisar o clima escolar como método na busca pela identificação das reformas necessárias ao ambiente escolar. A avalição do clima, portanto, pode contribuir expressivamente com informações sobre o que vai bem e o que pode ser melhorado na escola, fundamentando projetos que visem a intervenção e a prevenção de fatores que afetam o contexto escolar de forma negativa, o que contribuirá para um processo de ensino-aprendizagem de qualidade e melhora das relações (THAPA et. al., 2013).

Embora amplamente discutido em outros países, o clima escolar é pouco estudado no Brasil, sendo escasso o número de instrumentos validados para sua avaliação e adaptados à realidade escolar brasileira. Em vista disso, o Grupo de Estudos e Pesquisas em Educação Moral - GEPEM Unicamp/ Unesp, iniciou em 2014 uma pesquisa ${ }^{1}$, que teve como um dos objetivos construir, testar e validar três instrumentos para avaliar o clima escolar em alunos do 70 ano em diante, docentes e gestores do Ensino Fundamental e Ensino Médio. Para seu desenvolvimento contou com a participação de escolas públicas e particulares, de diferentes estados brasileiros, totalizando uma amostra de aproximadamente 12.000 indivíduos. 0 trabalho aqui apresentado faz parte dessa pesquisa maior e teve como objetivo compreender e avaliar o clima escolar em alunos, docentes e gestores do ensino fundamental $\left(7^{\circ}\right.$ ao $9^{\circ}$ ano) e ensino médio de escolas pública e privada em uma cidade do interior do estado de Mato Grosso do Sul.

A definição de clima escolar envolve uma ambiguidade de conceitos e de variáveis a serem considerados em sua classificação. Segundo Cunha (2014), o termo é definido de forma diversa por pesquisadores que 0 investigam adotando diferentes métodos e abordagens; entretanto, os estudos se convergem ao se referirem às características específicas que caracterizam o clima em cada instituição.

O que esses estudos têm em comum é o entendimento de que o clima escolar envolve a percepção que os sujeitos que compõe o ambiente escolar têm sobre o meio onde estão inseridos (CUNHA; COSTA, 2009; GAZIEL, 1987; JANOSZ, 1998; LOUKAS, 2007; THIÉBAUD, 2005). Nesse sentido, entendemos como clima escolar o conjunto de percepções individuais e coletivas sobre a instituição de ensino, os fatores que compõe sua organização, suas estruturas pedagógicas, administrativas e as relações de convívio que ocorrem no ambiente escolar ${ }^{2}$.

\footnotetext{
${ }^{1}$ Pesquisa "Em busca de caminhos que promovam a convivência respeitosa em sala de aula todos os dias: investigando o clima escolar", coordenada por Telma P. Vinha (Unicamp) e Alessandra de Morais (UNESP) e composta por equipe de pesquisadores do GEPEM e pesquisadores de diferentes universidades do Brasil. Financiamento da Fundação de Amparo à Pesquisa do Estado de São Paulo (FAPESP) e Fundação Lemann.

${ }^{2}$ Definição adotada pelo Grupo de Estudos e Pesquisas em Educação Moral - GEPEM Unicamp/ Unesp.
} 
Então, a percepção dos sujeitos sobre o clima envolve uma análise subjetiva de todos os envolvidos dentro da instituição escolar sobre a qualidade do trabalho que é desenvolvido, os relacionamentos, os valores e sentimentos, ou seja, refere-se a uma "personalidade coletiva" sobre a instituição escolar; assim, cada escola constitui o seu próprio clima. Ele determina a qualidade de vida e a produtividade dos docentes, dos alunos e permite-nos conhecer aspectos morais da escola. Nota-se, portanto, a importância de estudar e compreender o clima escolar por meio da percepção de todos os agentes escolares.

No que se refere as variáveis que constituem o clima escolar, os estudos sobre o tema também revelam uma multiplicidade de definições adotados por diferentes pesquisadores. Na pesquisa de Gomes (2005), por exemplo, observa-se que as dimensões que constituem o clima escolar variam muito e que os fatores que o compõe são: atmosfera de ordem; satisfação e importância atribuída a um clima de ordem; normas e regulamentos; sanções e recompensas, absenteísmo e evasão; e boa conduta dos alunos. Já as pesquisas realizadas nos Estados Unidos pelo Conselho Nacional do Clima Escolar consideram que uma avaliação efetiva do clima deva se concentrar em quatro dimensões: segurança, relações, ensino e aprendizagem e ambiente institucional (VINHA et. al., 2016).

No presente estudo, as dimensões que consideramos serem constituintes do clima escolar são: as relações com o ensino e com a aprendizagem; as relações sociais e os conflitos na escola; as regras, sanções e segurança na escola; as situações de intimidação entre alunos; a família, a escola e a comunidade; a infraestrutura e a rede física da escola; as relações com o trabalho; a gestão e a participação. Vale ressaltar que o clima escolar deve ser entendido como a inter-relação entre tais dimensões.

Ao analisar o clima escolar, portanto, espera-se que as instituições possam adquirir conhecimentos que possibilite planejar ações conjuntas de intervenção em busca de um clima positivo em seu cotidiano. Tais objetivos se colocam diante da necessidade de reconhecer o ambiente escolar como espaço favorável à aprendizagem da convivência democrática e ao desenvolvimento da autonomia moral. Para tanto, estudiosos em educação vêm demonstrando cada vez mais a importância de adotarmos uma concepção de escola como lugar onde, não apenas se ensinam conhecimentos e se transmite conteúdos, mas também onde se aprende a viver com os outros e a respeitá-los (SERRANO, 2002).

Assim, é importante que as ações escolares frente aos problemas nas relações interpessoais sejam pautadas numa atuação preventiva pensada desde a educação para a convivência ética na escola (DEL REY; ORTEGA; FERIA, 2009; ORTEGA, 2006; DIAZ-AGUADO, 2010; TOGNETTA; VINHA, 2012, ZECHI, 2014, entre outros). Educação essa que tem como objetivo o desenvolvimento de um clima escolar positivo, contribuindo para a melhora nas relações sociais e da qualidade do ensino, e estabelecer as bases da educação para a formação cidadã. Estamos defendendo que a escola deve assumir um currículo que permita aos alunos aprender a conviver de forma democrática, suscitando a sensibilidade ética e educando os indivíduos enquanto cidadãos que respeitam os demais e se faz respeitar (ZECHI, 2014).

Diante dos objetivos propostos, o presente artigo apresenta os resultados da avaliação do clima escolar realizada em uma escola pública no interior do estado do Mato Grosso do Sul, discutindo os principais problemas elencados pelos membros da comunidade escolar enquanto subsídios que podem orientar ações futuras para a melhora da qualidade da convivência escolar.

\section{MÉTODOS}

A avaliação do clima escolar se deu por meio de questionário construído e validado pelo GEPEM Unesp/Unicamp (VINHA; MORAIS; MORO, 2017). Foram elaborados três tipos de questionários adaptados às escolas brasileiras, direcionados aos alunos do $7^{\circ}$ ano do ensino fundamental ao 3 o ano do ensino médio, seus professores e gestores. Os questionários foram construídos em formato Likert, contendo quatro pontos (escala de 1 a 4), assim, ao ler as afirmações os participantes tinham quatro opções de respostas, como por exemplo: 1-Não concordo, 2-Concordo pouco, 3-Concordo e 4Concordo muito. Os instrumentos possuem uma seção socioeconômica e itens que contemplam as oito dimensões inter-relacionadas e consideradas constituintes do Clima Escolar: 
Quadro 1. Matriz de referência das dimensões constituintes do Clima escolar

\begin{tabular}{|c|c|c|}
\hline \multicolumn{3}{|c|}{ CLIMA ESCOLAR - MATRIZ } \\
\hline DIMENSÃO & CONCEITO & GRUPO \\
\hline $\begin{array}{l}\text { 1. As relações com o } \\
\text { ensino e com a } \\
\text { aprendizagem }\end{array}$ & $\begin{array}{l}\text { A boa qualidade desta dimensão se assenta na percepção da escola } \\
\text { como um lugar de trabalho efetivo com o conhecimento, que } \\
\text { investe no êxito, motivação, participação e bem-estar dos alunos, } \\
\text { promove o valor da escolarização e o sentido dado às } \\
\text { aprendizagens. Supõe também a atuação eficaz de um corpo } \\
\text { docente estável e a presença de estratégias diferenciadas, que } \\
\text { favoreçam a aprendizagem de todos, e o acompanhamento } \\
\text { contínuo, de maneira que nenhum aluno fique para trás. }\end{array}$ & $\begin{array}{l}\text { Aluno } \\
\text { Professor } \\
\text { Gestor }\end{array}$ \\
\hline $\begin{array}{l}\text { 2. As relações sociais e } \\
\text { os conflitos na escola }\end{array}$ & $\begin{array}{l}\text { Refere-se às relações, aos conflitos e à percepção quanto à } \\
\text { qualidade do tratamento entre os membros da escola. Abrange } \\
\text { também a identificação pelos adultos das situações de intimidação } \\
\text { e maus tratos vivenciadas nas relações entre pares, e a } \\
\text { corresponsabilidade dos profissionais da escola nos problemas de } \\
\text { convivência. A boa qualidade do clima relacional é resultante das } \\
\text { relações positivas que ocorrem nesse espaço, das oportunidades de } \\
\text { participação efetiva, da garantia do bem-estar, respeito e apoio } \\
\text { entre as pessoas, promovendo continuamente o sentimento de } \\
\text { pertencimento. }\end{array}$ & $\begin{array}{l}\text { Aluno } \\
\text { Professor } \\
\text { Gestor }\end{array}$ \\
\hline $\begin{array}{l}\text { 3. As regras, as } \\
\text { sanções e a segurança } \\
\text { na escola }\end{array}$ & $\begin{array}{l}\text { Esta dimensão diz respeito a como gestores, professores e alunos } \\
\text { intervêm nos conflitos interpessoais na escola. Abrange a } \\
\text { elaboração, conteúdo, legitimidade e equidade na aplicação das } \\
\text { regras e sanções, identificando também os tipos de punição } \\
\text { geralmente empregados. Compreende, ainda, a ordem, justiça, } \\
\text { tranquilidade, coerência e segurança no ambiente escolar. }\end{array}$ & $\begin{array}{l}\text { Aluno } \\
\text { Professor } \\
\text { Gestor }\end{array}$ \\
\hline $\begin{array}{l}\text { 4. As situações de } \\
\text { intimidação entre } \\
\text { alunos }\end{array}$ & $\begin{array}{l}\text { Esta dimensão trata da identificação de situações de intimidação e } \\
\text { maus tratos nas relações entre pares e de bullying, e dos locais em } \\
\text { que ocorrem. }\end{array}$ & Alunos \\
\hline $\begin{array}{l}\text { 5. Família, escola e } \\
\text { comunidade }\end{array}$ & $\begin{array}{l}\text { Refere-se à qualidade das relações entre escola, família e } \\
\text { comunidade, compreendendo o respeito, a confiança e o apoio } \\
\text { entre esses grupos. Abrange a atuação da escola, considerando as } \\
\text { necessidades da comunidade. Envolve o sentimento de ser parte } \\
\text { integrante de um grupo que compartilha objetivos comuns. }\end{array}$ & $\begin{array}{l}\text { Aluno } \\
\text { Professor } \\
\text { Gestor }\end{array}$ \\
\hline $\begin{array}{l}\text { 6. A infraestrutura e a } \\
\text { rede física da escola }\end{array}$ & $\begin{array}{l}\text { Trata-se da qualidade da infraestrutura e do espaço físico da escola, } \\
\text { de seu uso, adequação e cuidado. Refere-se a como os } \\
\text { equipamentos, mobiliários, livros e materiais estão preparados e } \\
\text { organizados, para favorecer a acolhida, o livre acesso, a segurança, } \\
\text { o convívio e o bem-estar nesses espaços. }\end{array}$ & $\begin{array}{l}\text { Aluno } \\
\text { Professor } \\
\text { Gestor }\end{array}$ \\
\hline $\begin{array}{l}\text { 7. As relações com o } \\
\text { trabalho }\end{array}$ & $\begin{array}{l}\text { Trata-se dos sentimentos dos gestores e professores em relação a } \\
\text { seu ambiente de trabalho e às instituições de ensino. Abrange as } \\
\text { percepções quanto à formação e qualificação profissional, às } \\
\text { práticas de estudos e reflexões sobre as ações, à valorização, } \\
\text { satisfação e motivação para a função que desempenham, e ao } \\
\text { apoio que recebem dos gestores e demais profissionais. }\end{array}$ & $\begin{array}{l}\text { Professor } \\
\text { Gestor }\end{array}$ \\
\hline $\begin{array}{l}\text { 8. A gestão e } \text { a } \\
\text { participação }\end{array}$ & $\begin{array}{l}\text { Abrange a qualidade dos processos empregados para identificação } \\
\text { das necessidades da escola, intervenção e avaliação dos resultados. } \\
\text { Inclui também a organização e articulação entre os diversos setores } \\
\text { e atores que integram a comunidade escolar, no sentido de } \\
\text { promover espaços de participação e cooperação, na busca de } \\
\text { objetivos comuns. }\end{array}$ & $\begin{array}{l}\text { Professor } \\
\text { Gestor }\end{array}$ \\
\hline
\end{tabular}

Fonte: GEPEM - Grupo de Estudos e Pesquisas em Educação Moral - UNESP/UNICAMP (VINHA; MORAIS; MORO, 2017) 
O estudo aqui apresentado foi realizado em duas escolas, uma instituição pública e outra da rede privada, de ensino fundamental e médio em uma cidade no interior do Estado de Mato Grosso do Sul. Para a coleta de dados, os pesquisadores reuniram-se com a equipe gestora das escolas apresentando os objetivos e metodologia do estudo e convidando-as para participarem da pesquisa.

$\mathrm{Na}$ escola pública foram aplicados 400 questionários, dentre estes responderam 382 alunos, 16 docentes e 2 gestores. Na escola privada foram aplicados 121 questionários, dentre estes 114 alunos, 5 com docentes e 2 gestores. No presente texto será apresentado os dados referentes à escola pública.

A partir dos dados coletados, procedeuse às análises estatísticas descritivas conforme as variáveis em estudo. Elaboramos tabelas de frequência das variáveis categóricas (itens de clima escolar), com valores de frequência absoluta (n) e percentual (\%), e estatísticas descritivas dos dados numéricos (escores dos itens). Com base em tais análises, e a partir do cálculo da pontuação média obtida em cada dimensão, identificou-se as percepções gerais dos grupos como positiva, intermediária ou negativa. Para isso, os quatro pontos da escala Likert foram divididos em tercis, sendo atribuído ao primeiro tercil a pontuação de 1 a 2,25 (nível negativo); ao segundo tercil, de 2,26 a 2,75 (nível intermediário); e ao terceiro tercil de 2,76 a 4,00 (nível positivo).

A pesquisa foi submetida à apreciação da
Comissão de Ética em Pesquisa da Faculdade de Ciências Médicas da UNICAMP, recebendo parecer favorável para sua execução (CAAE: 32973114.2.0000.5404).

\section{RESULTADOS}

Participaram da pesquisa 382 discentes do $7^{\circ}$ ano do ensino fundamental ao 3o ano do ensino médio, 16 docentes e 2 gestores. Dentre os alunos, $45,7 \%$ são do sexo masculino e $54,3 \%$ do sexo feminino.

Quando questionados a respeito do nível de estudo que pretendem se graduar no futuro, $1 \%$ dos alunos respondeu que pretende concluir o ensino fundamental; $6 \%$ ensino médio; $3 \%$ ensino profissionalizante; $50 \%$ faculdade; e $41 \%$ pretendem fazer pós-graduação. Em relação aos estudos, $31 \%$ responderam estar muito bem; $41 \%$ bem; $25,5 \%$ nem tão bem, mas nem tão mal; e $2,5 \%$ mal. Ao serem indagados sobre a quantidade de bons amigos que possuem na escola, $58 \%$ responderam quatro ou mais; $33 \%$, dois ou três; $8 \%$ possuem um bom amigo e $1 \%$ nenhum.

Analisando a percepção geral na perspectiva dos três membros da comunidade escolar - alunos, professor e gestor, os gráficos 1 e 2 mostram os dados das dimensões "as relações sociais e os conflitos na escola" e "as regras, as sanções e a segurança na escola". Nessas dimensões as avaliações são, em sua maioria, positivas havendo poucas divergências entre os respondentes.

Gráfico 1. As relações sociais e os conflitos na escola.

Fonte: Autores (2018)

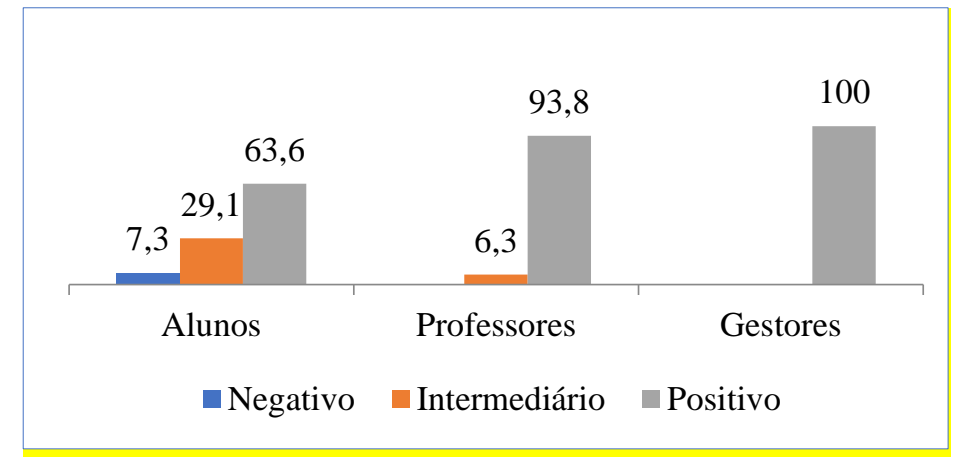


Gráfico 2. As regras, as sanções e a segurança na escola.

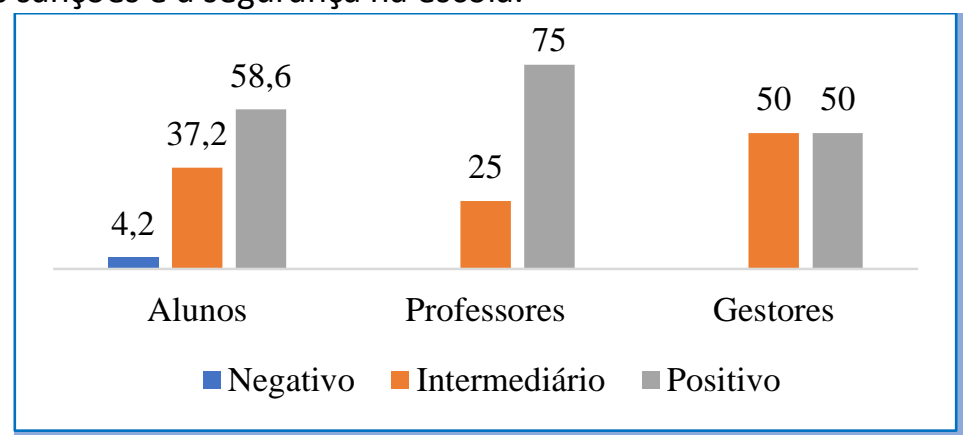

Fonte: Autores (2018)

O gráfico 3 "A infraestrutura e a rede física na escola" e o gráfico 4 "A família, a escola e a comunidade" são as avaliações que mais tendem ao negativo e intermediário entre os três grupos de respondestes.

Gráfico 3. A infraestrutura e a rede física na escola

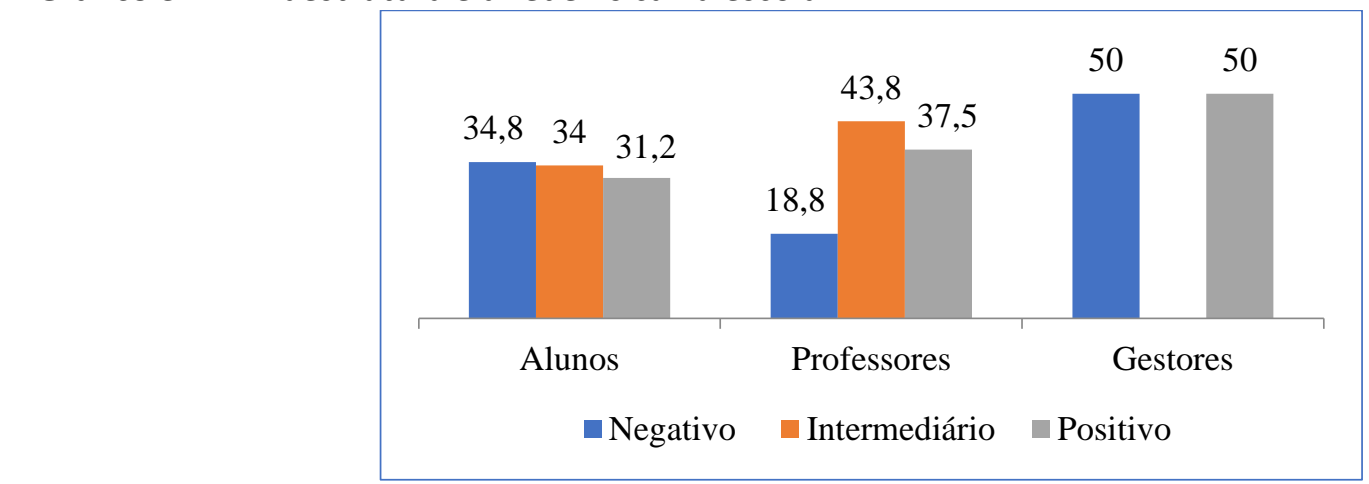

Fonte: Autores (2018)

Gráfico 4. A família, a escola e a comunidade.

Fonte: Autores (2018)

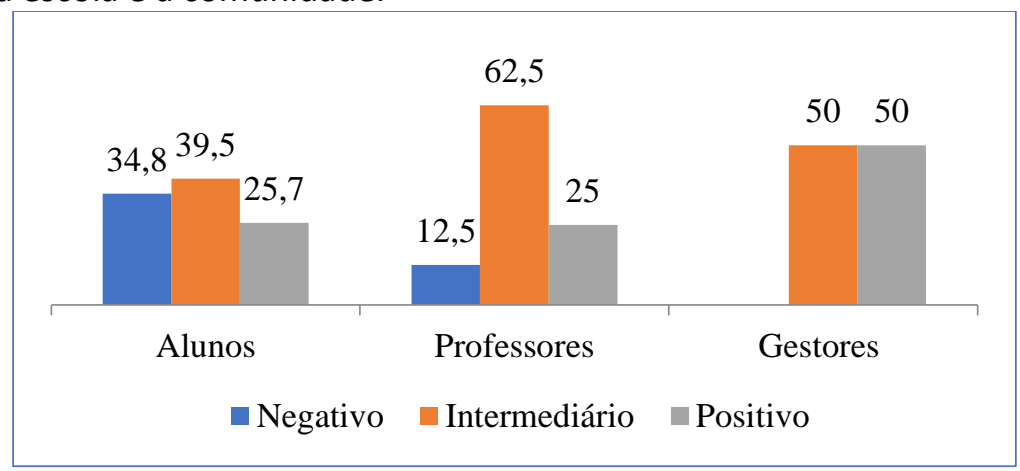

Os dados a seguir revelam divergências nas percepções dos grupos. Na dimensão "As situações de intimidação entre os alunos" (Gráfico 5) a maioria dos discentes tem uma percepção positiva; no entanto, chama atenção a quantidade de docentes $(43,8 \%)$ que apresentam uma avaliação negativa. 
Gráfico 5. As situações de intimidação entre alunos.

Fonte: Autores (2018)

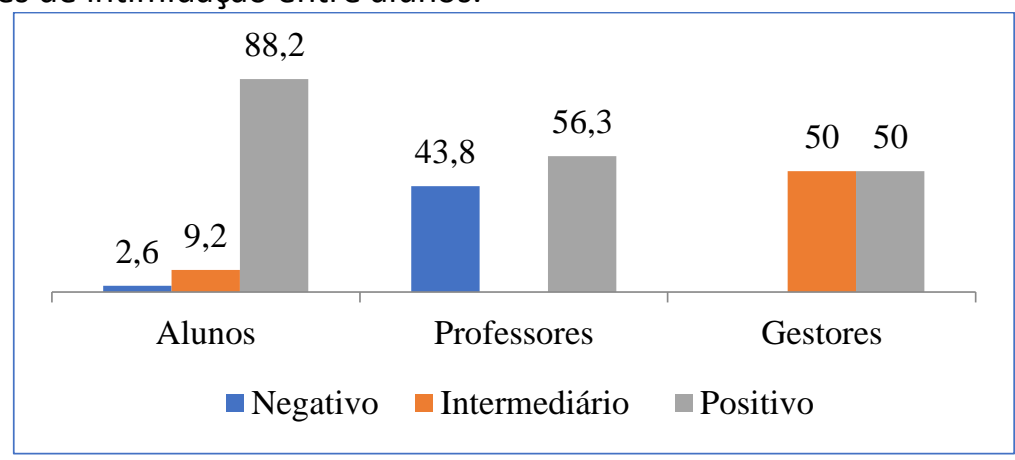

Na dimensão "As relações com o ensino e enquanto as avaliações dos alunos tendem ao a aprendizagem" (Gráfico 6) há uma avaliação intermediário, destacando alguns itens negativos. positiva da maioria dos professores; a percepção dos gestores se divide entre neutra e positiva;

Gráfico 6. As relações com o ensino e com a aprendizagem

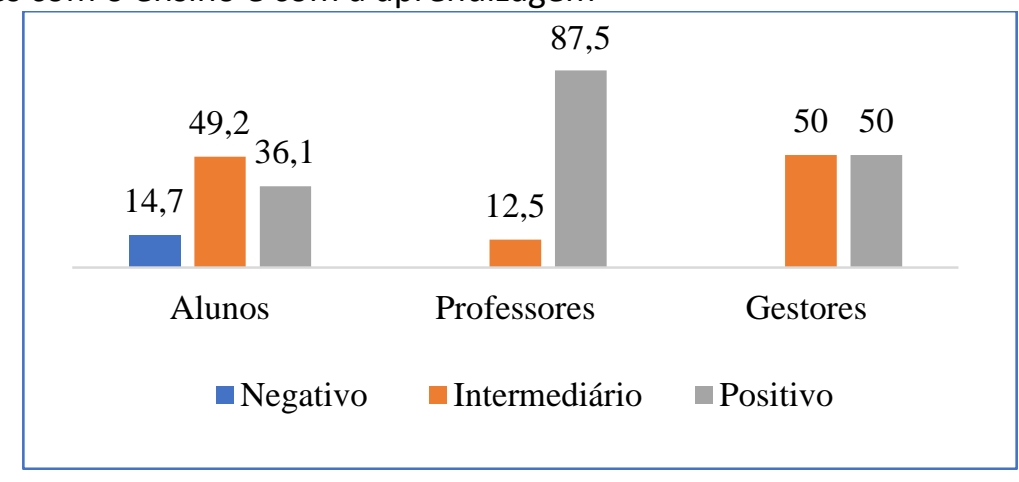

Fonte: Autores (2018)

Também encontramos divergências nas respostas dadas as dimensões "As relações com o trabalho" (Gráfico 7) e "A gestão e a participação" (gráfico 8), presentes nos questionários dos professores e gestores, destacando-se uma avaliação mais negativa dos professores em relação aos gestores.

Gráfico 7. As relações com o trabalho.

Fonte: Autores (2018)

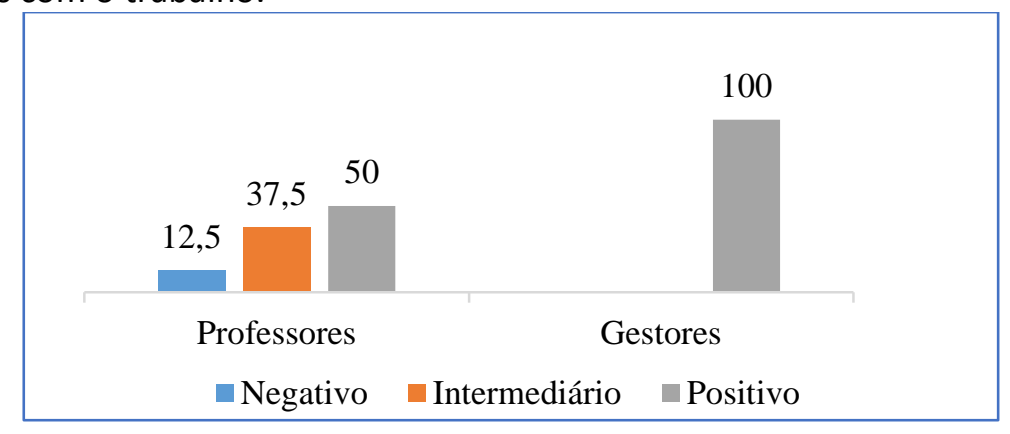


Gráfico 8. A gestão e a participação.

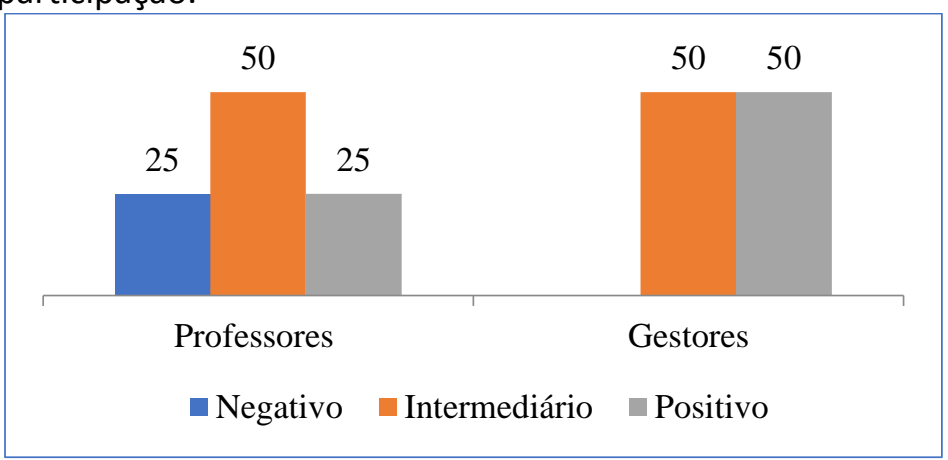

Fonte: Autores (2018)

A análise das percepções gerais, conforme apresentada, contribui para mostrar em que as avaliações são consistentes e em que divergem entre os grupos (alunos, professores e gestores). As divergências encontradas podem ser consideradas como um recurso importante na busca de um maior diálogo entre os membros da escola visando um planejamento coletivo para a melhora da qualidade do clima escolar e, em decorrência, da convivência.

Por outro lado, a avaliação do clima requer a leitura dos itens que compõem cada dimensão para, assim, a escola conhecer o que vai bem e o que precisa ser melhorado. Desse modo, analisou-se os itens que compõem as dimensões, destacando questões importantes para a melhora da qualidade da convivência em meio escolar.

Na dimensão "as regras, as sanções e a segurança na escola", embora a percepção geral tenda ao positivo, alguns itens avaliados mais negativamente sinalizam que são escassos os momentos destinados à discussão das regras e dos problemas de convivência. Todos os gestores e a maioria dos alunos (76\%) e professores $(81,3 \%)$ responderam que os estudantes pouco ou nunca participam da elaboração e das mudanças de regras do ambiente escolar.

Correlacionado a esse resultado, mais da metade dos alunos afirmaram que pouco ou nunca compreendem e têm conhecimento sobre as regras da escola. Também, boa parte $(70 \%)$ dos alunos, $60 \%$ dos professores e todos os gestores responderam que pouco ou nunca há momentos e espaços para discussão dos problemas de convivência, de disciplina e de regras. La Taille (2006) nos traz que as normas escolares devem ser construídas com a participação de todos, refletindo junto aos alunos sobre os princípios que levaram a construção de tais regras, sua relevância e as consequências de não as cumprir. O respeito em relação a uma regra ocorre mais frequentemente quando a mesma foi formulada juntamente com os alunos. Assim, as decisões em sala de aula, devem ocorrer juntamente com a classe, dando oportunidade para que os jovens regulem seus próprios comportamentos, promovendo assim a justiça, sentimentos de responsabilidade e de propriedade (RAMOS; WREGE; VICENTIN, 2012).

Em relação ao item "Os conflitos são resolvidos de forma justa para os envolvidos", parte considerável dos alunos (47\%) respondeu que algumas vezes ou nunca essa afirmação é frequente, enquanto a maioria (69\%) dos professores e todos os gestores responderam muitas vezes. É importante que todos os membros da comunidade escolar sintam que há justiça nas resoluções de conflitos, o que fortalece a compreensão das necessidades das regras e do seguimento das mesmas para o bom convívio e respeito (LICCIARDI; RAMOS, 2012).

Em relação às atitudes tomadas diante de conflitos e desobediências as regras, os alunos responderam que as atitudes mais frequentes são o encaminhamento para a direção - $69 \%$ dos discentes selecionaram a opção, informar a família sobre o ocorrido (62\%), dar advertência (41\%) e suspensão (45\%). Os professores responderam que as ações mais frequentes são informar os responsáveis sobre o ocorrido pedindo que tomem providência (88\%) e ouvir os alunos e os incentivar a buscar soluções para os problemas $(81 \%)$, dado último que se contradiz com as respostas dos discentes. Os gestores responderam que frequentemente os alunos são suspensos e recebe advertência, além da escola informar os responsáveis sobre o ocorrido pedindo que tomem providência, assim como, os alunos são ouvidos e convidados a reparar seus erros. As ações tomadas como as mais frequentes sinalizam a falta de preparo dos educadores e 
gestores em lidar com tais situações, muitas vezes tendo atitudes autoritárias que focam nas punições.

Tognetta e Vinha (2012) apontam que, em caso de conflitos e desobediência às regras, as escolas deveriam adotar sanções por reciprocidade, ou seja, as ações deveriam estar relacionadas com o ato cometido. Assim, atitudes como suspensão, advertência, dentre outras ações punitivas frequentemente utilizadas não contribuirão para a resolução do problema. 0 aluno deve compreender seus erros por meio de diálogo e participação deste nos processos de elaboração das regras e sanções; no entanto, este espaço não é oferecido a eles.

Os itens avaliados na dimensão "as relações sociais e os conflitos na escola" sinalizam a percepção de que há uma boa qualidade das relações estabelecidas na escola, com poucos conflitos. Ao serem questionados sobre a satisfação sentida nas relações sociais com os colegas, funcionários, coordenadores/orientadores e gestores, cerca de $70 \%$ dos alunos e professores responderam que estão satisfeitos ou muito satisfeitos, com destaque para as relações dos alunos com os funcionários ( $84 \%$ ) e seus colegas (77\%). Todos os gestores também responderam que estão satisfeitos em seus relacionamentos na escola, exceto entre eles próprios, nesse caso, um deles respondeu não estar satisfeito na sua relação com o outro.

Em concordância com esses dados, ao serem questionados se "Há muitas situações de conflitos entre os alunos e os professores", a maioria dos participantes concordam pouco ou não concordam com a frequência de tais situações de conflito. Contudo, é preciso questionar a baixa percepção sobre a ocorrência de conflitos, especialmente por parte dos docentes e gestores que, na dimensão "as situações de intimidação entre alunos", responderam que a ocorrência de conflitos entre os alunos é frequente.

Conforme afirma Vinha (2013), partindo de uma perspectiva construtivista, os conflitos são naturais e necessários para o desenvolvimento das crianças, sendo boas oportunidades para se trabalhar os valores e as regras. As intervenções não devem ter como foco a resolução do conflito em si (o produto), mas sim o processo, isto é, a forma como serão resolvidos os problemas. Os conflitos devem ser reconhecidos como oportunidades para ajudar os alunos a compreenderem suas perspectivas e a dos outros, buscando assim soluções respeitosas e cooperativas para todos os envolvidos. No entanto, os itens analisados na dimensão "as regras, as sanções e a segurança na escola" mostram que não há espaço para discussão dos conflitos e elaboração das regras na escola.

Outro exemplo de divergência entre as respostas encontra-se na questão "Eu fui agredido, maltratado, intimidado, ameaçado, excluído ou humilhado por algum colega da escola", em que a grande maioria dos alunos $(85 \%)$ respondeu nunca, enquanto os professores (68\%) e todos os gestores responderam que essas situações ocorrem algumas vezes entre os alunos. Também, ao serem questionados se os alunos provocam, zoam, apelidam ou irritam algum colega na escola, as respostas dos professores e gestores ficaram divididas entre algumas e muitas vezes. Tal percepção dos adultos da escola deve ser refletida entre os membros da instituição, considerando que o bullying é um sério problema que afeta a vida social da escola como um todo, podendo trazer consequências negativas para os alunos e prejudicando a boa convivência escolar (ORTEGA, 2006).

Na dimensão "as relações com o ensino e com a aprendizagem" destaca-se um sentimento de descrença entre $52 \%$ dos alunos e $40 \%$ dos professores quanto ao futuro dos estudantes da escola pública em relação ao êxito realizando faculdade, mesmo que a grande maioria deles, $94 \%$ dos professores e $93 \%$ dos alunos, tenha considerado que o aprendizado passado pela escola seja útil para a vida dos discentes.

A importância de avaliar tal dimensão é salientada pelo fato do clima escolar positivo promover a capacidade do aluno em aprender, favorecendo a aprendizagem cooperativa, a coesão do grupo, o respeito, participação e a confiança mútua, ou seja, o clima escolar é importante para o sucesso da instituição influenciando na qualidade do processo de ensino-aprendizagem (LIRA, 2010; THAPA et al, 2013).

Entre as dimensões que mais tendem a uma avaliação negativa destaca-se na "infraestrutura e a rede física da escola" o item "as salas de aula são confortáveis, limpas e conservadas (carteiras e mesas adequadas, boa iluminação e ventilação, não há ruídos)", em que grande parte dos alunos (75\%) e dos professores $(62,5 \%)$ disse que algumas vezes ou nunca tal situação ocorre. Na dimensão "a família, a escola 
e a comunidade", indagados se a família está contente com a escola, $73 \%$ dos alunos, $81 \%$ dos professores e todos os gestores responderam sempre ou muitas vezes; em contrapartida, a participação da família nas atividades e eventos promovidos pelas escolas não são tão frequentes segundo a metade dos alunos. Sobre a questão "Há oportunidade para os pais participarem das decisões tomadas pela escola", a maioria dos alunos (65\%) respondeu algumas vezes ou nunca; já em relação ao item "Sua escola realiza projetos ou trabalhos de ajuda à comunidade ou ao bairro" há um consenso entre os respondentes que pouco ou nunca ocorrem tais momentos. Estudo realizado por Del Rey, Ortega e Feria (2009) nos traz que a qualidade da convivência é percebida de forma mais positiva nas escolas em que os familiares têm uma maior participação na escola; também, estudo realizado por Lira (2010) confirma que a má condição da estrutura física da escola afetava de forma negativa o ambiente e, consequentemente, o clima escolar.

Nas dimensões avaliadas somente pelos professores e gestores, ao analisarem "as relações com o trabalho", 94\% dos professores afirmaram que se sentem motivados e com vontade de dar aulas; porém se sentem pouco (44\%) ou nada (12,5\%) satisfeitos com o desempenho profissional dos gestores. Em contrapartida, todos os gestores responderam que se sentem satisfeitos com seu próprio desempenho profissional como também com o trabalho dos professores de sua escola, mas se sentem pouco motivados em relação ao desempenho de suas funções. Sobre a afirmação "Todos agem como se realmente se sentissem responsáveis pela escola e fazem a sua parte", $69 \%$ dos professores e todos os gestores concordaram pouco ou não concordaram com tal afirmação.

Ao analisar "a gestão e a participação", $81 \%$ dos professores consideraram que a equipe gestora conhece claramente os problemas e as necessidades da escola. Entretanto, para os gestores os professores não têm muito conhecimento sobre as necessidades e problemas da escola. Ainda, a participação dos diversos atores na construção do projeto pedagógico da escola e a participação dos professores nas decisões relacionadas à vida escolar foram avaliados negativamente pela maioria dos professores e gestores. Uma gestão democrática e a articulação entre os diversos atores que integram a comunidade escolar no sentido de promover espaços de participação e cooperação é um dos caminhos necessários para a melhora da convivência.

Quanto ao item "A minha escola oferece oportunidades de estudo, de qualificação e de formação aos seus profissionais", os professores (69\%) e gestores responderam que concordam pouco ou não concordam. A formação docente tem sido apontada como um dos pilares na busca para a melhora da qualidade da convivência, assim, a escola deve garantir um processo de formação continuada enquanto espaço de reflexão coletiva a respeito das necessidades da instituição (ZECHI, 2014).

\section{CONSIDERAÇÕES FINAIS}

Uma avaliação sobre o clima escolar permite que cada um expresse como se sente em sua escola; fornece uma "fotografia" do ambiente socioeducativo a partir do conjunto de percepções de todos os atores da instituição, sem particularizar; promove um reconhecimento do que está acontecendo (tantos dos pontos fortes quanto dos vulneráveis); demonstra que a opinião de todos é importante, incentivando-os a expressá-la; facilita a escolha das áreas em que a escola quer direcionar ações futuras; mobiliza as pessoas para desenvolver os projetos no estabelecimento e proporciona uma avaliação durante ou após um processo de transformação na instituição (THIÉBAUD, 2005).

Os resultados da avaliação do clima, portanto, representam a "personalidade coletiva" do contexto investigado. Refletem a influência dos valores institucionalizados subjacentes, bem como dos sistemas de crenças, normas, ideologias, rituais e tradições que constituem a cultura da escola.

Ao avaliar as dimensões que compõem o clima escolar, destaca-se que as percepções dos três grupos analisados, em geral, são positivas. A percepção mais positiva sob o ponto de vista dos alunos se deu na dimensão "as situações de intimidação entre alunos", já a avaliação mais positiva sob o ponto de vista dos docentes e gestores foi sobre a dimensão "as relações sociais e os conflitos". A avaliação mais negativa na perspectiva de todos os participantes foi sobre a dimensão "a infraestrutura e a rede física da escola".

A análise dos itens que compõem as dimensões traz informações importantes para a escola com relação à percepção dos integrantes sobre aquilo que está indo bem e não tão bem 
assim, permitindo a identificação de aspectos a serem melhorados.

Contudo, há que se considerar que o diagnóstico dos problemas e dificuldades, assim como o planejamento das intervenções e propostas a serem desenvolvidas, não podem se restringir apenas aos resultados obtidos a partir da avaliação do clima escolar. É importante também que se busquem outros dados, inclusive qualitativos. Muitas vezes, dimensões avaliadas positivamente contém itens negativos que afetam a qualidade do clima escolar e a escola ainda não consegue perceber como problemáticas tais questões. Como ilustração dessa ideia temos a dimensão das regras, as sanções e a segurança na escola em que alunos e professores não consideraram que tinham problemas que precisavam ser revistos.

Dessa forma, os dados de avaliação do clima devem ser discutidos coletivamente entre todos os atores envolvidos no processo educacional para a elaboração de intervenções que atuem nas dificuldades encontradas. As ações devem partir de uma necessidade compartilhada na escola e seus membros têm de ser sensibilizados e estarem dispostos a se envolverem na transformação.

É de fundamental importância a implantação de estratégias coordenadas e sistêmicas que promovam, de fato, um clima escolar positivo em que ocorra a valorização dos atores escolares (alunos, pais, professores e gestores) e o exercício constante do diálogo e do trabalho coletivo. A melhoria da escola requer ações intencionais e planejadas que promovam o desenvolvimento moral, ético e social dos alunos, assim como, um ambiente participativo, justo, respeitoso, saudável e seguro para todos.

\section{AGRADECIMENTOS}

Agradecemos a Fundação Universidade Federal de Mato Grosso do Sul pelo financiamento da presente pesquisa na modalidade Bolsa de Iniciação Científica.

\section{REFERÊNCIAS}

BLAYA, C et al. Clima y violencia escolar. Un estudio comparativo entre España y Francia. Revista de Educación, n. 339, p. 293-315, 2006.

CUNHA, M. B. Possíveis relações entre percepções de violência dos alunos, clima escolar e eficácia coletiva. Educação e Pesquisa, São Paulo, v. 40, n. 4, p. 1077-1092, out-dez. 2014.
DOI: $10.1590 / S 1517-97022014005000010$.

Disponível em:

http://www.scielo.br/scielo.php?script=sci_arttex t\&pid=S1517-

$97022014000400014 \& \operatorname{lng}=p t \& t \operatorname{lng}=p t$. Acesso em: out. 2016

CUNHA, M. B.; COSTA, M. O clima escolar de escolas de alto e baixo prestigio. In: REUNIÃO DA ASSOCIAÇÃO NACIONAL DE PÓS-GRADUAÇÃO E PESQUISA EM EDUCAÇÃO: SOCIEDADE, CULTURA E EDUCAÇÃO: NOVAS REGULAÇÕES, 32., Caxambu-MG., Anais... Caxambu: Associação nacional de Pesquisa em Educação, 2009.

DEL REY, R.; ORTEGA, R.; FERIA, I. Convivencia escolar: fortaleza de la comunidad educativa y protección ante la conflictividad escolar. Revista Interuniversitaria de Formación del Profesorado, n. 66, p. 129-158, 2009. Universidad de Córdoba.

DIAZ-AGUADO, M. J. (coord). Estudio estatal sobre la convivencia escolar en la educación secundaria obligatoria. Madri: Ministerio de Educación, Secretaría De Estado De Educación Y Formación Profesional, 2010.

GAZIEL, H. H. O clima psico-social da escola e a satisfação que os docentes do segundo grau encontram no seu trabalho. Le travail Humain, tome 50, n.1, pp. 35-45, 1987.

GOMES, C.A., A Escola de Qualidade para Todos: Abrindo as Camadas da Cebola. Revista Ensaio: Avaliação, Políticas Públicas e Educação, Rio de Janeiro, v.13, n.48, p. 281-306, jul./set. 2005.

JANOSZ, M. et al. L'environnement socioéducatif à l'école secondaire: un modele théorique pour guider l'évaluation du milieu, Revue Canadienne de Psychoéducation, v. 27, n. 2, 1998. Disponível em <http://www.f-d.org/climatecole/Janoszarticle-1998.pdf.>. Acesso em: set. 2015.

LA TAILLE, J. M. Y. Moral e ética: dimensões intelectuais e afetivas. Porto Alegre: Artmed, 2006.

LICCIARDI, L. M. S., RAMOS, A. M. Por onde começar a superação da violência na escola? A implantação de um ambiente cooperativo e o trabalho com a construção do conhecimento. In: TOGNETTA, L. R. P.; VINHA, T. P. (orgs). É possível superar a violência na escola? Construindo 
caminhos pela formação moral. São Paulo:

Editora do Brasil, Faculdade de

Educação/UNICAMP, 2012. p. 19 - 37.

LIRA, A. A organização escolar: a relação entre clima e violências. 2010. 207 f. Dissertação (Mestrado em Educação), Universidade Católica de Brasília, Brasília, 2010.

LOUKAS, A. What is school climate? High-quality school climate is advantageous for all students and may be particularly beneficial for at-risk students. Leadership Compass, Virginia, Estados Unidos, v. 5, n. 1, 2007.

MORO, A. A construção e as evidências de validade de instrumentos de medida para avaliar o clima escolar. 2018, 470f. Tese (Doutorado em Educação), Universidade Estadual de Campinas, Faculdade de Educação. Campinas - SP, 2018.

ORTEGA, R. La convivencia: un modelo de prevención de la violencia. In: Moreno, A.; Soler, M. P. (Coords.). La convivencia en las aulas, problemas y soluciones. Madrid: Ministerio de Educación y Ciencia. 2006.

RAMOS, A. M.; WREGE, M. G.; VICENTIN, V. F. A organização das regras e assembleias em sala de aula: Obedecer à autoridade ou aos princípios? in: TOGNETTA, L. R. P.; VINHA, T. P. (orgs) É possível superar a violência na escola?Construindo caminhos pela formação moral. São Paulo: Editora do Brasil, Faculdade de Educação/UNICAMP,2012. V. 1.

SERRANO, G. P. Educação em valores: como educar para a democracia. 2. ed. Tradução de Fátima Murad. Porto Alegre: Artmed, 2002.

THAPA, A. et al. A Review of School Climate Research. Review of Educational Research. AERA. v. 83, n. 3, p. 357-385, set. 2013. Disponível em: < http://rer.aera.net>. Acesso em: nov. 2015.

THIÉBAUD, M. Climat scolaire. p. 1-6. 2005. Disponível em <http://www.relationsansviolence.ch/climatscolaire-mt.pdf.>. Acesso em: dez. de 2015.

TOGNETTA, L. R. P.; VINHA, T. P. (orgs). É possível superar a violência na escola? Construindo caminhos pela formação moral. São Paulo: Editora do Brasil, Faculdade de Educação/UNICAMP, 2012.

VINHA, T. P. Os conflitos interpessoais na escola. In: GARCIA, J.; TOGNETTA, L. R. P.; VINHA, T. P. Indisciplina, conflitos e bullying na escola. Campinas: Mercado de Letra, 2013. p. 61 - 90. vol. 2 (Coleção desconstruindo a violência na escola: os meus, os seus e os nossos bagunceiros).

VINHA, T. P.; MORAIS, A.; MORO, A. 2017. Manual de orientação para a aplicação dos questionários que avaliam o clima escolar. Campinas: FE/UNICAMP, 2017. 77 p.

VINHA, T. P. Et al. O clima escolar e a convivência respeitosa nas instituições educativas. Est. Aval. Educ., São Paulo, v. 27, n. 64, p. 96-127, jan/abr. 2016.

ZECHI, J. A. M. Educação em valores: solução para a violência e a indisciplina na escola? 250f. 2014. Tese (Doutorado em Educação). Universidade Estadual Paulista, UNESP, Presidente Prudente, 2014.

Submetido em: $26 / 11 / 2018$

Aceite Final em: 13/12/2018 